Research Article

\title{
Self-Expanding Metallic Stent Fracture in the Treatment of Malignant Biliary Obstruction
}

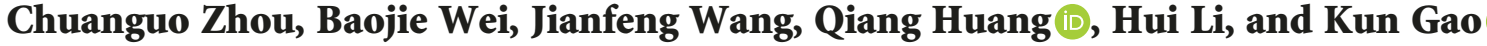 \\ Department of Interventional Radiology, Beijing Chaoyang Hospital, Affiliated Hospital of Capital Medical University, \\ Beijing 100020, China \\ Correspondence should be addressed to Kun Gao; gao_kun123456789@sina.com
}

Received 16 November 2017; Revised 13 December 2017; Accepted 18 December 2017; Published 10 April 2018

Academic Editor: Michel Kahaleh

Copyright (c) 2018 Chuanguo Zhou et al. This is an open access article distributed under the Creative Commons Attribution License, which permits unrestricted use, distribution, and reproduction in any medium, provided the original work is properly cited.

\begin{abstract}
Background. Palliative therapies for malignant biliary obstruction (MBO) include choledochojejunostomy and self-expanding metallic stent (SEMS) insertion. Fractures following SEMS insertion in MBO treatment are scarce. Objective. To assess the clinical features of biliary stent fractures and evaluate associated factors. Methods. One hundred fifty-six consecutive patients who underwent biliary SEMS placement for MBO treatment at Beijing Chaoyang Hospital affiliated to Capital Medical University, in 2010-2015, were evaluated retrospectively. Demographics, clinical features, stent parameters and patency times, and survival times were collected. Across the ampulla of Vater, balloon dilatation, number of stents, stent patency time, and survival time were compared between the stent and nonstent fracture groups. Results. There were 168 biliary metallic stents inserted in 156 patients, including 144 and 12 patients with one and 2-3 stents, respectively. Pre- and/or postballoon dilation was performed in 107 patients. Stents across and above the duodenal papilla were used in 105 and 51 patients, respectively. Six cases (3.8\%) with stent occlusion had stent fractures. Single- and multiple-stent fracture rates were $4 / 144(2.8 \%)$ and $2 / 12$ (16.7\%), respectively. Fracture times after stent deployment were 126.8 \pm 79.0 (median, 115.5) days. Stent patency times in the stent and nonstent fracture groups were 151.8 \pm 67.8 (median, 160.5) days and 159.3 \pm 73.6 (median, 165.5) days, respectively. Overall survival times in the stent and nonstent fracture groups were $399.7 \pm 147.6$ (median, 364.0) days and $283.7 \pm 126.1$ (median, 289.0) days, respectively. Conclusion. Stent fractures following MBO treatment constitute a relatively rare long-term complication. Though there were no factors found to be significantly associated with SEMSs fracture, a trend could be observed towards more fractures in multistent, transpapillary, and balloon dilation groups.
\end{abstract}

\section{Introduction}

Malignant biliary obstruction (MBO) refers to the blockage of the biliary tree by direct malignant tumor infiltration or external compression; the underlying malignancies in the vast majority of cases are cholangiocarcinomas and pancreatic head carcinomas. Other tumors in this region include cystic, duodenal, and gastric cancers, as well as intrahepatic and hilar lymph node metastases [1]. Commonly, the clinical manifestation of $\mathrm{MBO}$ is painless jaundice, with anorexia and weight loss. Infection secondary to malignant bile duct obstruction may result in cholangitis, symptoms of the digestive tract, hepatic failure and renal insufficiency, sepsis, and even death. Despite recent advances in radiology, only approximately $20 \%$ of periampullary tumors are resectable at the time of diagnosis, because of invasiveness, metastasis, and poor performance status [2]. The available options for palliative therapy of malignant biliary tree obstruction include choledochojejunostomy, percutaneous external/ internal drainage or metallic stent placement, and endoscopic techniques. Recent evidence indicates the superiority of self-expanding metallic stents (SEMSs) over plastic stents, with regard to stent patency time, complications rates, and reinterventions. In selected subgroups of patients, SEMS placement may have survival benefits [3]. Short-term complications of SEMS insertion include cholangitis, asymptomatic increase of amylase levels, and bleeding. Long-term complications comprise stent occlusion due to tumor 
ingrowth or overgrowth, stent migration, and viscus perforation [4]. Few reports have described stent fractures following SEMS insertion in the treatment of malignant biliary obstruction [5-11]. The present study aimed at assessing the clinical features of biliary stent fractures in six cases and identifying factors that may affect biliary stent fractures.

\section{Materials and Methods}

The study was reviewed and approved by the ethics committees of Beijing Chaoyang Hospital affiliated to Capital Medical University according to the standards of the Declaration of Helsinki. Written informed consent was waived because of the retrospective nature of this study. All patient records were anonymized and deidentified before analysis.

A total of 156 consecutive patients who underwent biliary SEMS placement with percutaneous transhepatic approach for the treatment of MBO at Beijing Chaoyang Hospital affiliated to Capital Medical University between January 2010 and September 2015 and were not suitable for surgery or declined resection for poor performance status were enrolled in this retrospective study. Most of the patients with malignant biliary obstruction were accompanied by cholangitis. To the patients which have no cholangitis but with obvious gastrointestinal symptoms accompanied by intrahepatic biliary dilatation and serum total bilirubin above $150 \mu \mathrm{mol} / \mathrm{L}$, they were also treated by biliary drainage and stent implantation. Obstruction location, stent type, number of stents placed, placement across the duodenal ampulla, and predilation or postdilation were recorded. If applicable, stent fracture data were extracted from patient records and relevant imaging findings. Malignant biliary obstructions include "distal" and "proximal" obstruction types. Distal biliary obstruction refers to an obstruction below the main hepatic ducts' confluence. In such cases, the entire biliary tree could be drained with a single stent without requiring an external catheter.

\section{Interventional Procedure}

According to preoperative computed tomography scan (CT) or magnetic resonance imaging (MRI) data, the optimal puncture point in most cases was $2-4 \mathrm{~cm}$ below the right cardiophrenic angle at the axillary midline. A 22-gauge doublewalled needle, for example, the Chiba needle, was advanced under fluoroscopic guidance. The stylet was removed, and the contrast agent was gently injected while retracting the needle until opacification of the bile duct. Once the target bile duct was accessed, a $0.018^{\prime \prime}$ wire was advanced into the duct through a coaxial system, and the wire was upsized to a $0.035^{\prime \prime}$ guide wire. A 7.0-8.5 French biliary drainage catheter (COOK Inc., Bloomington, IN, United States) was inserted into the dilated biliary duct under wire guidance. Two to four weeks later, serum total bilirubin levels were decreased to almost normal amounts, and cholangitis was controlled, with the patient's general condition improved. Then, the uncovered nitinol SEMSs (COOK Inc., Bloomington, IN, United States) were implanted. Through an $8 \mathrm{~F}$ sheath, a directional catheter in combination with a hydrophilic guide wire was used to cross the biliary obstruction and advanced into the small bowel. An appropriately sized stent may be inserted, usually 8 or $10 \mathrm{~mm}$ in diameter and 40 to $100 \mathrm{~mm}$ in length. According to the degree of biliary stenosis and stent expansion, pre- or postdilation with balloon catheter was selected. Cholangiography via the sheath after stent deployment was used to assess stent patency. In case of satisfactory contrast agent flow, the sheath was removed, with the puncture tract plugged with gel foam pledges. Stent fracture was defined as persistent or recurrent jaundice, and cholangiography revealed bile duct obstruction, with interruption of biliary stent continuity or deficiency of the biliary stent segment.

\section{Perioperative Treatment}

All patients received $150 \mathrm{mg}$ of magnesium isoglycyrrhizinate, $40 \mathrm{mg}$ of pantoprazole, and $6 \mathrm{~g}$ (three doses) of cefoxitin sodium intravenously guttae at the day of the procedure. Continuous intravenous infusion of octreotide $0.3 \mathrm{mg}$ was administered before procedure to prevent acute pancreatitis. Postoperative serum amylase levels were used to determine whether to continue intravenous octreotide administration. Nausea, vomiting, abdominal pain, and other symptoms were treated as well. The patients were followed up via outpatient appointments or by telephone interviews every 3 months to 1 year after the procedure. The last follow-up occurred in May 2017.

\section{Statistical Analysis}

Statistical analyses were performed with the SPSS 22.0 software (SPSS, United States). Quantitative data are expressed as mean $\pm \mathrm{SD}$ and were compared by unpaired $t$-test; categorical variables were compared by the Chi-square test or Fisher's exact test. Stent patency time and survival time were derived by the Kaplan-Meier method and compared using the log-rank test. Two-tailed $P<0.05$ was considered statistically significant.

\section{Results}

A total of 156 patients were treated during the study period, including 94 men $(65.6 \pm 11.4$ years old) and 62 women $(68.6 \pm 12.0$ years old). Biliary obstructions in these patients were pancreatic cancer $(n=72)$, cholangiocarcinoma $(n=$ $40)$, malignant gastric carcinoma $(n=21)$, cancer of the ampulla of Vater $(n=10)$, gallbladder carcinoma $(n=7)$, colon cancer metastasis $(n=3)$, lung cancer metastasis $(n=$ 2 ), and ovary cancer metastasis $(n=1)$. The success rate of the biliary stent procedure was $100 \%$. A successful procedure consists of gastrointestinal symptoms relieved, total bilirubin decreased to almost normal, and biliary stent well positioned and patent. All patients had "distal" biliary obstruction. The most common short-term complications included cholangitis, asymptomatic amylase increase, and biliary bleeding. Long-term complications comprise stent occlusion due to tumor ingrowth or overgrowth and stent fractures. There were no patients who had stent migration, viscus perforation, or seeding (Table 1). 
TABLE 1: The most common short- and long-term complications of SEMS deployment in the 156 patients.

\begin{tabular}{lcc}
\hline & Type of complications & Patients \\
\hline & Cholangitis & $33(21.2 \%)$ \\
Short-term complications & Asymptomatic amylase increase & $21(13.5 \%)$ \\
& Biliary bleeding & $(5.1 \%)$ \\
& Ingrowth & $86(55.1 \%)$ \\
Long-term complications & Overgrowth & $43(27.6 \%)$ \\
& Stent fractures & $6(3.8 \%)$ \\
\hline
\end{tabular}

TABle 2: Demographic characteristics, across/above the ampulla, balloon dilation, number of stents, stent patency time, and survival time of the 156 study patients.

\begin{tabular}{lccc}
\hline & Nonstent fracture $(n=150)$ & Stent fracture $(n=6)$ & \multicolumn{1}{c}{$P$ value $\chi^{2}$} \\
\hline Sex, M/F & $90 / 60$ & $4 / 2$ & 0.107 \\
Mean age \pm SD, years & $67.1 \pm 11.6$ & $76.0 \pm 8.0$ & 1.852 \\
Above the ampulla, $n$ & 51 & 0 & 3.031 \\
Across the ampulla, $n$ & 99 & 6 & 0.07 \\
Nondilation, $n$ & 49 & 0 & 2.858 \\
Balloon dilation, $n$ & 101 & 6 & 0.10 \\
Single stent, $n$ & 140 & 4 & 5.778 \\
Multistent, $n$ & 10 & 2 & 0.07 \\
Stent patency time, days & $159.3 \pm 73.6$ (median, 165.5) & $151.8 \pm 67.8$ (median, 160.5) \\
Survival time, days & $283.7 \pm 126.1$ (median, 289.0) & $399.7 \pm 147.6$ (median, 364.0) & 0.414 \\
\hline
\end{tabular}

SD: standard deviation, ${ }^{*}$ Nonstent fracture versus stent fracture groups.

TABLE 3: Clinical characteristics of the six patients.

\begin{tabular}{|c|c|c|c|c|c|c|}
\hline Patient & Case 1 & Case 2 & Case 3 & Case 4 & Case 5 & Case 6 \\
\hline Age, gender & 62 , male & 81 , female & 82 , male & 82 , male & 71, male & 78 , female \\
\hline $\begin{array}{l}\text { Primary } \\
\text { disease }\end{array}$ & $\begin{array}{l}\text { Pancreatic } \\
\text { carcinoma }\end{array}$ & Pancreatic carcinoma & $\begin{array}{l}\text { Pancreatic } \\
\text { carcinoma }\end{array}$ & $\begin{array}{l}\text { Pancreatic } \\
\text { carcinoma }\end{array}$ & Cholangiocarcinoma & $\begin{array}{l}\text { Duodenal } \\
\text { ampulla } \\
\text { carcinoma }\end{array}$ \\
\hline $\begin{array}{l}\text { Level of } \\
\text { obstruction }\end{array}$ & Distal & Distal & Distal & Distal & Distal & Distal \\
\hline $\begin{array}{l}\text { Parameters of } \\
\text { stent }\end{array}$ & $10 \mathrm{~mm} \times 80 \mathrm{~mm}^{*}$ & $\begin{array}{c}\text { First stent, } \\
8 \mathrm{~mm} \times 60 \mathrm{~mm} ; \text { next two } \\
\text { stents, } 8 \mathrm{~mm} \times 60 \mathrm{~mm}\end{array}$ & $10 \mathrm{~mm} \times 60 \mathrm{~mm}$ & $8 \mathrm{~mm} \times 80 \mathrm{~mm}$ & $\begin{array}{c}\text { First stent, } \\
10 \mathrm{~mm} \times 40 \mathrm{~mm} \text {; second } \\
\text { stent, } 10 \mathrm{~mm} \times 100 \mathrm{~mm}\end{array}$ & $8 \mathrm{~mm} \times 60 \mathrm{~mm}$ \\
\hline $\begin{array}{l}\text { Number of } \\
\text { stents }\end{array}$ & One & Three & One & One & Two & One \\
\hline $\begin{array}{l}\text { Pre-/ } \\
\text { postdilation }\end{array}$ & Yes & Yes & Yes & Yes & Yes & Yes \\
\hline $\begin{array}{l}\text { Across the } \\
\text { ampulla }\end{array}$ & Yes & Yes & Yes & Yes & Yes & Yes \\
\hline $\begin{array}{l}\text { Time to stent } \\
\text { fracture } \\
(\text { days) }\end{array}$ & 89 & 37 & 65 & 179 & 142 & 249 \\
\hline $\begin{array}{l}\text { Patency time } \\
\text { of the stent } \\
\text { (days) }\end{array}$ & 89 & 187 & 65 & 179 & 142 & 249 \\
\hline $\begin{array}{l}\text { Overall } \\
\text { survival time } \\
\text { (days) }\end{array}$ & 241 & 312 & 335 & 393 & 662 & 455 \\
\hline
\end{tabular}

\footnotetext{
${ }^{*} 10 \mathrm{~mm}$ is the stent diameter and $80 \mathrm{~mm}$ the length. ${ }^{* *}$ Time to stent fracture is defined as the time period from last stent insertion to stent fracture.
} 


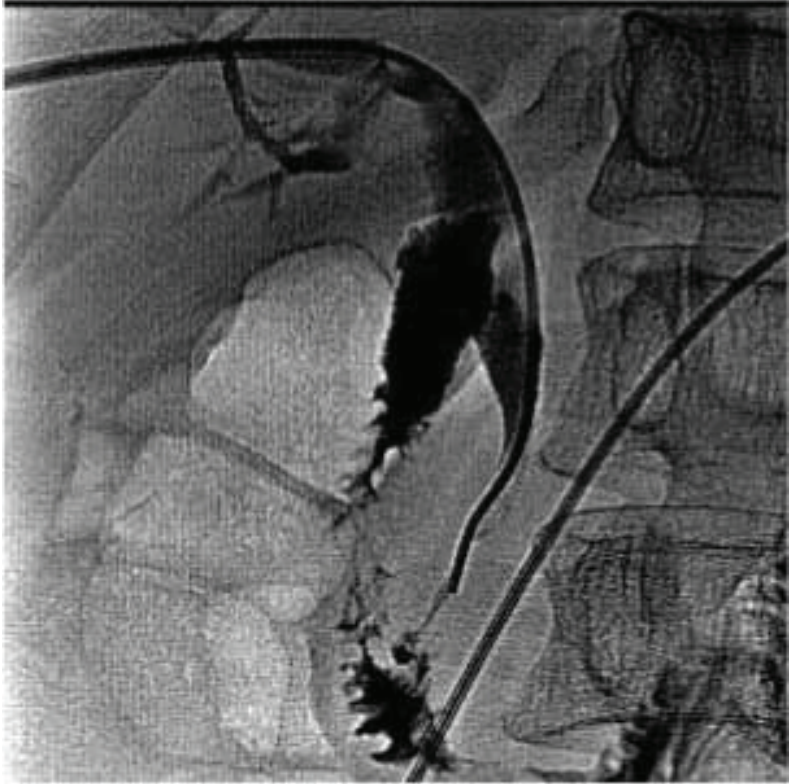

(a)

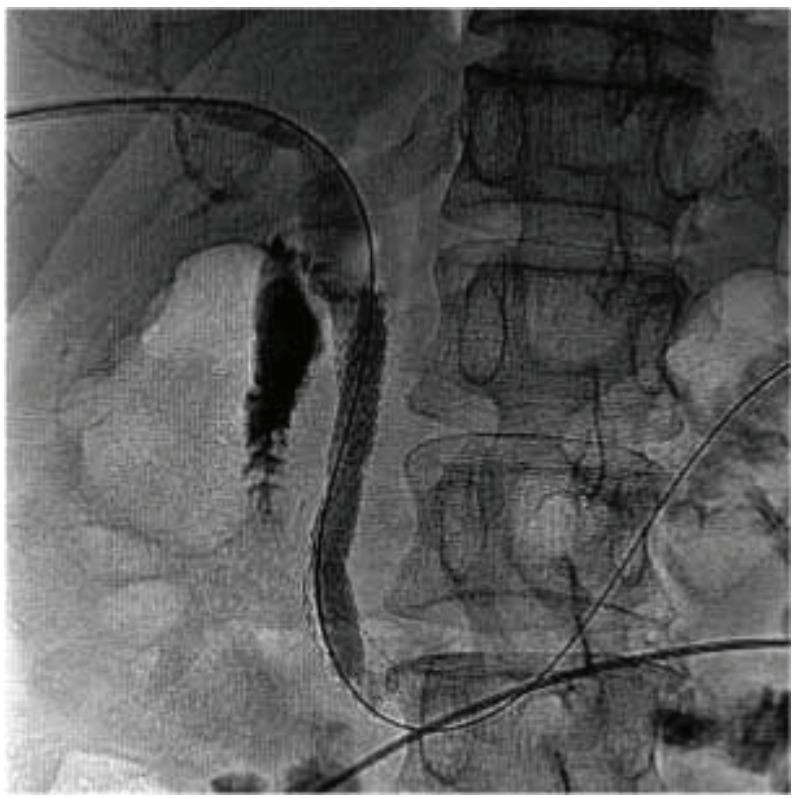

(c)

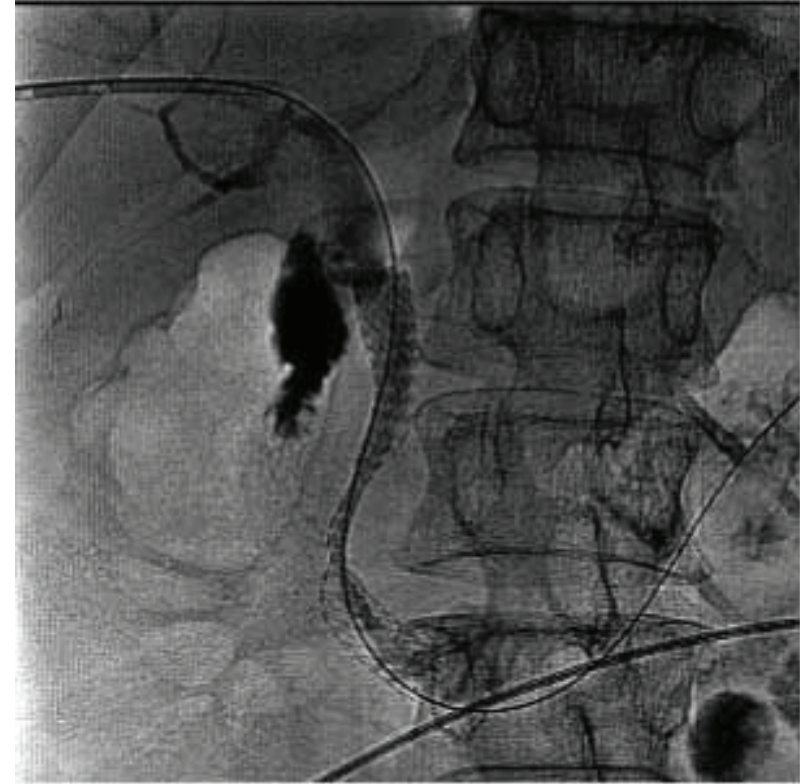

(b)

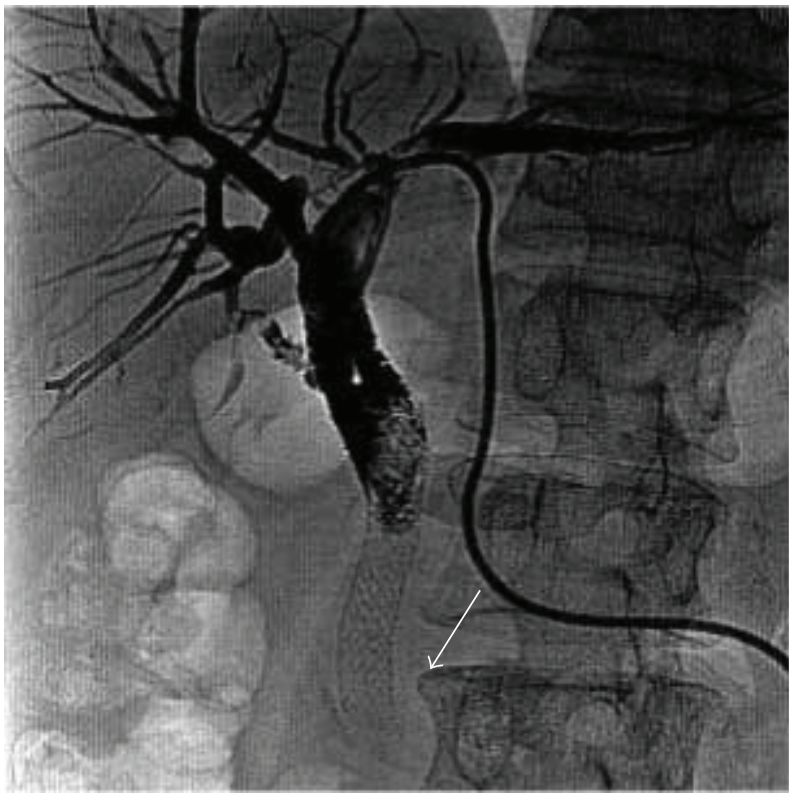

(d)

FIgURE 1: A 62-year-old male patient with pancreatic carcinoma whose common bile duct was severely obstructed by compression from pancreatic head carcinoma. (a) Contrast medium injection via the percutaneous transhepatic approach showing the distal common bile duct severely obstructed. (b) Five weeks later, a biliary stent (diameter, $10 \mathrm{~mm}$; length, $80 \mathrm{~mm}$; COOK Inc., Bloomington, IN, United States) was deployed in the distal common bile duct. The guidewire can be observed in the distal duodenum. The distal part of the stent protrudes into the duodenum. (c) Because of incomplete dilation of the biliary stent, a balloon (diameter, 8 mm; length, 40 mm; ATB5-3540-8-4.0; COOK Inc.) was used for biliary-plasty. (d) Eighty-nine days after stent placement, a left percutaneous transhepatic drainage catheter was placed for recurrent biliary obstruction. Cholangiography showed the biliary stent completely fractured (arrow) at the level of the stricture.

There were 168 biliary metallic stents inserted in 156 patients, including 144 and $12(7.7 \%)$ patients with one and 2-3 stents, respectively. Pre- and/or postballoon dilation was performed in 107 patients; the remaining patients did not undergo balloon dilation. Stent across and above the duodenal papilla was adopted in 105 and 51 patients, respectively. Six cases (3.8\%) with stent occlusion had stent fractures. Single- and multistent fracture rates were $4 / 144$ $(2.8 \%)$ and $2 / 12(16.7 \%)$, respectively. Mean and median fracture times after stent deployment were $126.8 \pm 79.0$ days and 115.5 days, respectively. Meanwhile, stent patency times in the stent and nonstent fracture groups were $151.8 \pm 67.8$ 


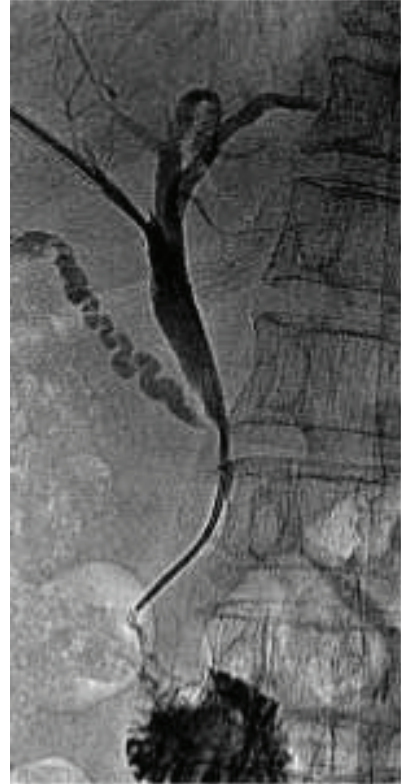

(a)

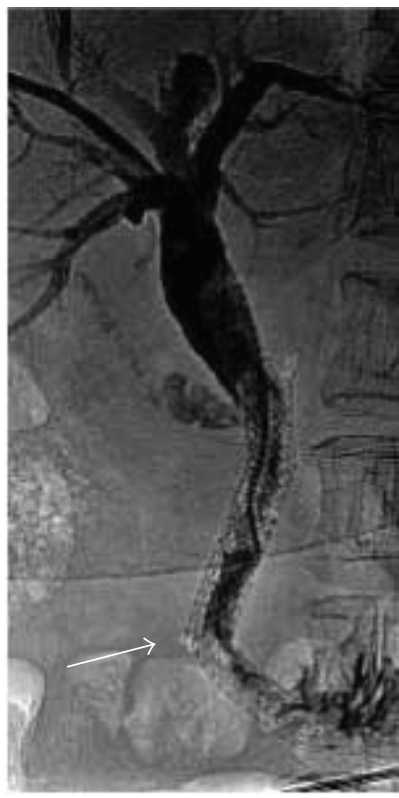

(d)

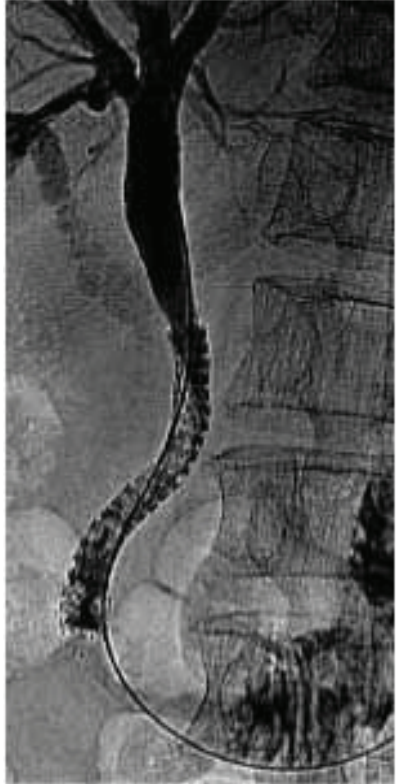

(b)

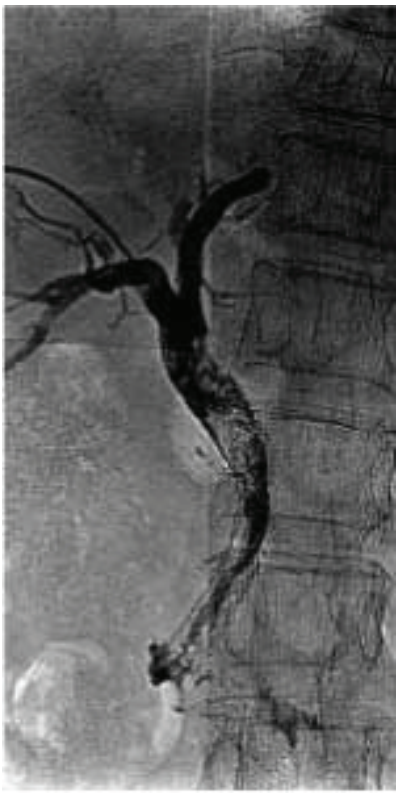

(e)

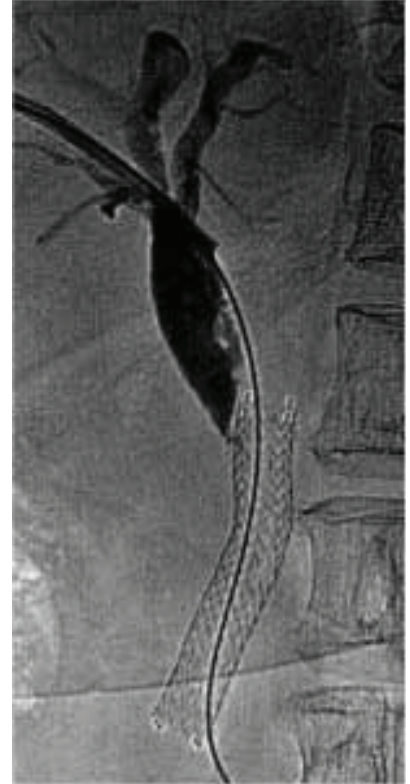

(c)

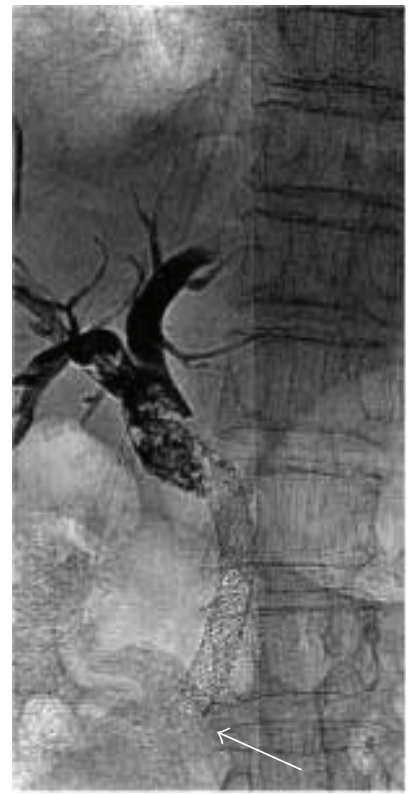

(f)

Figure 2: Complete stent fracture in an 81-year-old woman with common bile duct obstruction secondary to a cystic mass of the pancreatic head. (a). Percutaneous transhepatic cholangiogram depicting common bile duct stricture was shown. (b). Six weeks later, predilation (diameter, $8 \mathrm{~mm}$; length, $40 \mathrm{~mm}$; ATB5-35-40-8-4.0; COOK Inc.) was performed and a stent (diameter, $8 \mathrm{~mm}$; length, $60 \mathrm{~mm}$; COOK Inc., Bloomington, IN, United States) was inserted in the stricture, extending from the duodenum to the cystic duct. (c, d). Eleven months after biliary stent placement, the patient developed reobstructive jaundice, and percutaneous cholangiography showed stent occlusion. Two additional stents (diameter, $8 \mathrm{~mm}$; length, $60 \mathrm{~mm}$; COOK Inc., Bloomington, IN, United States) were deployed. An obtuse angle was formed distally between the two biliary stents (arrow). (e, f). Thirty-seven days after implantation of the two biliary stents, plain X-ray revealed the absence of the distal part of the stent (arrow), resulting from complete stent fracture. The fractured stent had therefore passed through the bowel without incident.

(median, 160.5) days and 159.3 \pm 73.6 (median, 165.5) days, respectively. Overall survival times in the stent and nonstent fracture groups were $399.7 \pm 147.6$ (median, 364.0) days and $283.7 \pm 126.1$ (median, 289.0) days, respectively. The characteristics of these six patients are summarized in Tables 2 and 3 and Figures 1-6.

\section{Discussion}

Biliary stent placement is widely used in the treatment of a variety of malignant biliary obstruction cases. For patients with malignant biliary obstruction and life expectancy exceeding 3 months, self-expandable metal stent deployment 


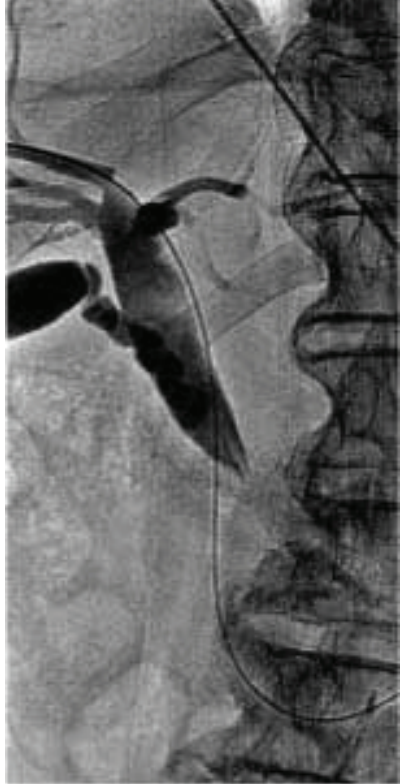

(a)

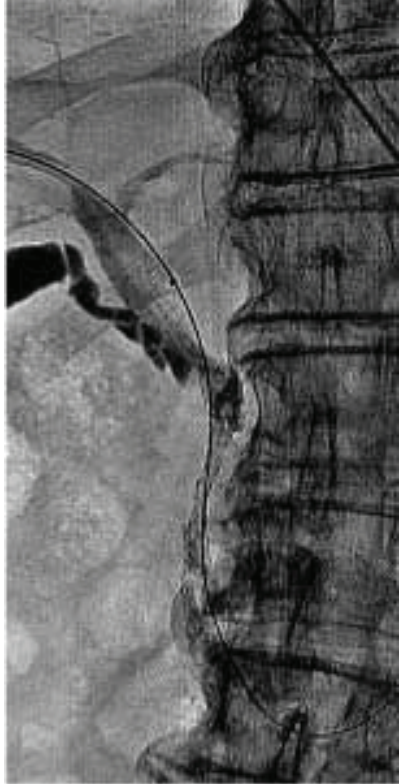

(b)

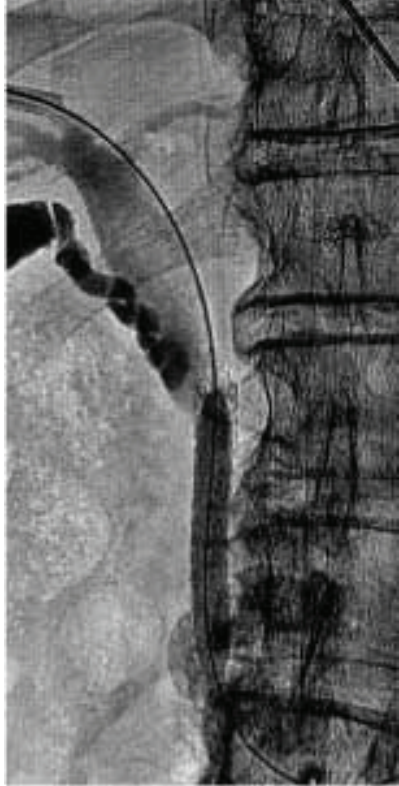

(c)

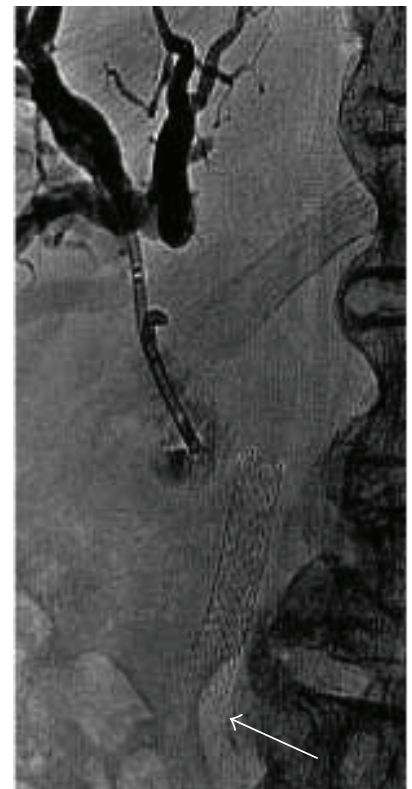

(d)

Figure 3: Complete stent fracture in a 79-year-old man with common biliary obstruction from pancreatic cancer. (a). Percutaneous transhepatic cholangiogram demonstrating severe stenosis of the distal common bile duct was shown. (b). After biliary decompression for 5 weeks, a metallic, self-expandable stent (diameter, $10 \mathrm{~mm}$; length, $60 \mathrm{~mm}$; COOK Inc., Bloomington, IN, United States) was inserted into the distal common bile duct. (c). Because of complete dilation of the biliary stent, a balloon (diameter, 8 mm; length, 40 mm; ATB5-35-408-4.0; COOK Inc.) was used for biliary-plasty. (d). Sixty-five days after stent deployment, percutaneous transhepatic cholangiography revealed biliary obstruction. The distal part of the stent was absent as a result of fracture (arrow). The fractured stent had therefore passed through the bowel without incident.

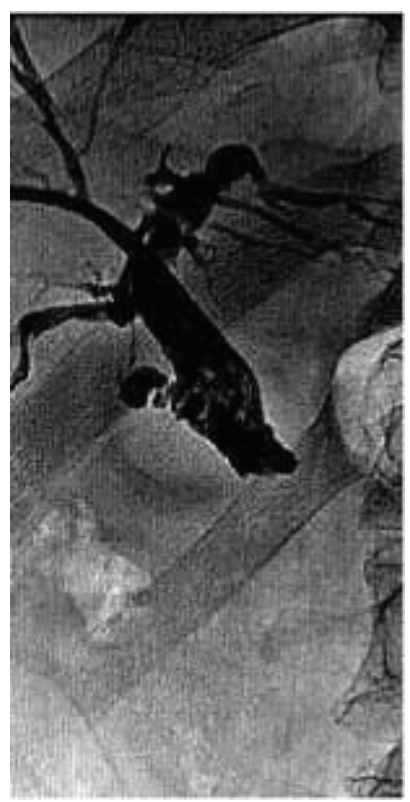

(a)

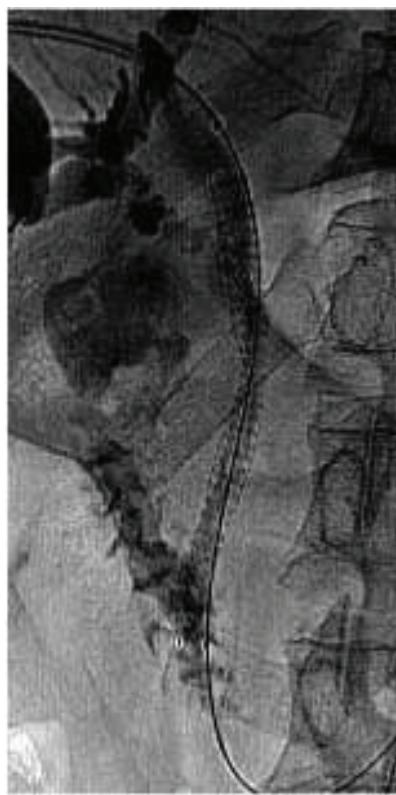

(b)

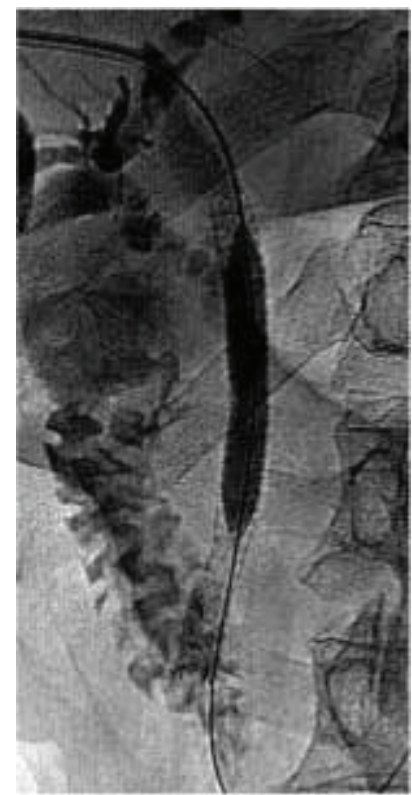

(c)

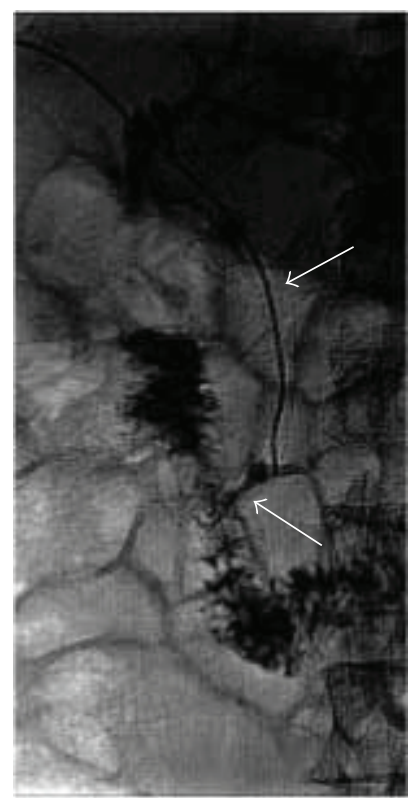

(d)

FIGURE 4: Complete stent fractures at two locations in an 82-year-old man with pancreatic cancer. (a). Percutaneous transhepatic cholangiogram demonstrating a stricture in the distal common bile duct was shown. Biliary decompression was performed with placement of a drainage catheter by the routine right approach. (b, c). Eight weeks later, a metallic self-expandable stent (diameter, $8 \mathrm{~mm}$; length, $80 \mathrm{~mm}$; COOK Inc., Bloomington, IN, United States) was inserted. Contrast medium injection after stent placement revealed stent patency. The distal part of the stent protruded into the duodenum. Postdilation was performed. (d). After 179 days, the patient developed recurrent jaundice. Percutaneous transhepatic cholangiography showed stent occlusion. There were two complete fracture sites in the metallic biliary stent (arrow), located at the upper biliary stenosis and duodenal ampulla, respectively. 


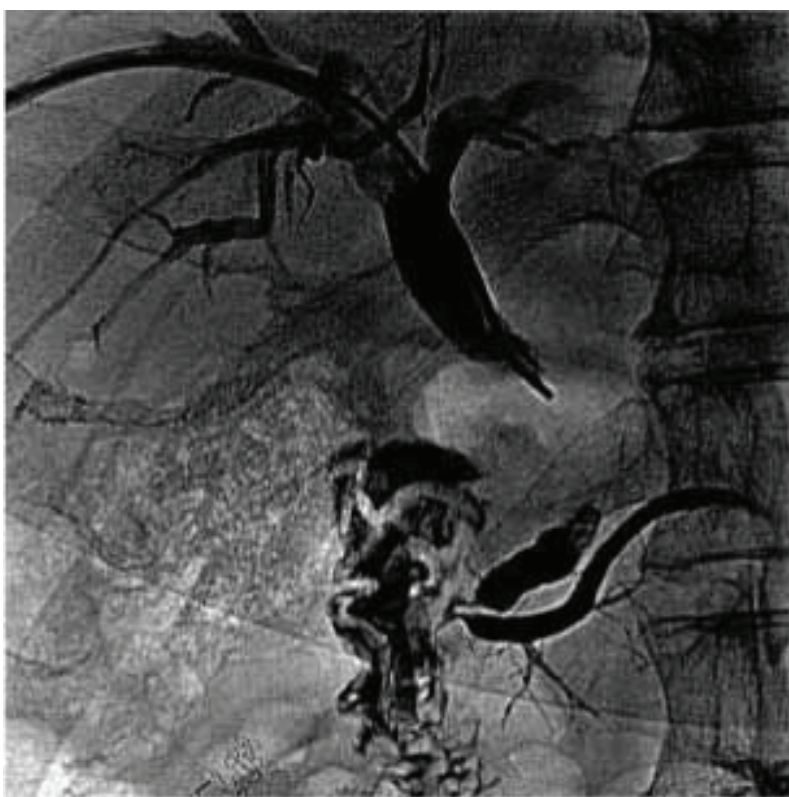

(a)

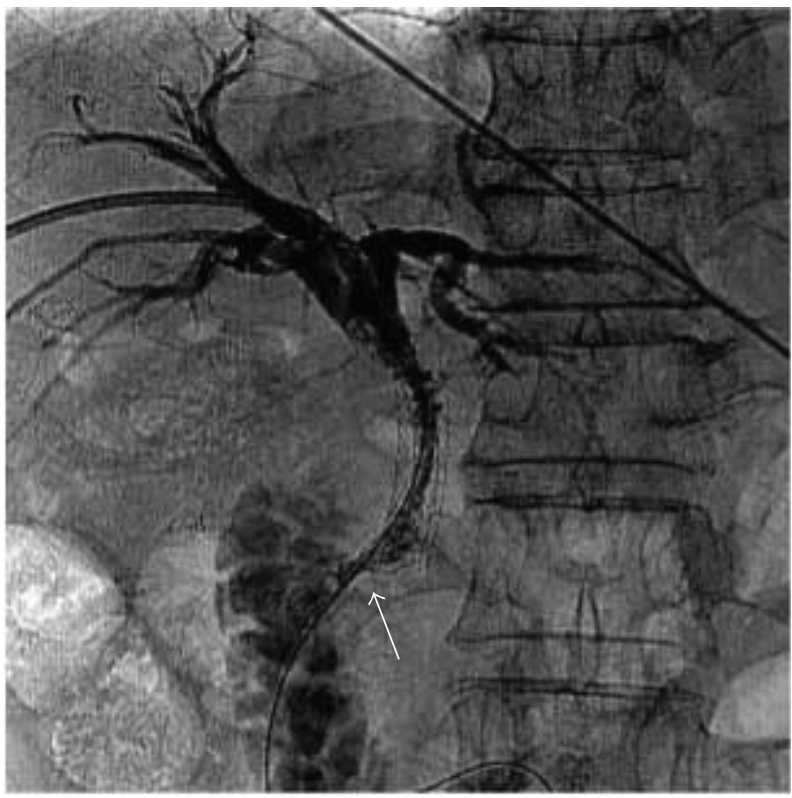

(c)

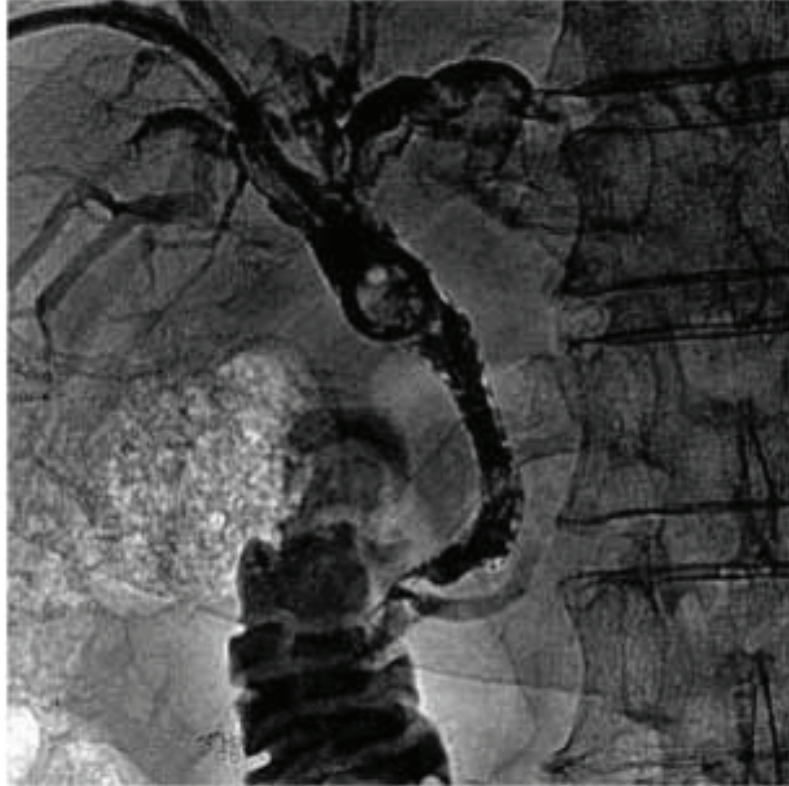

(b)

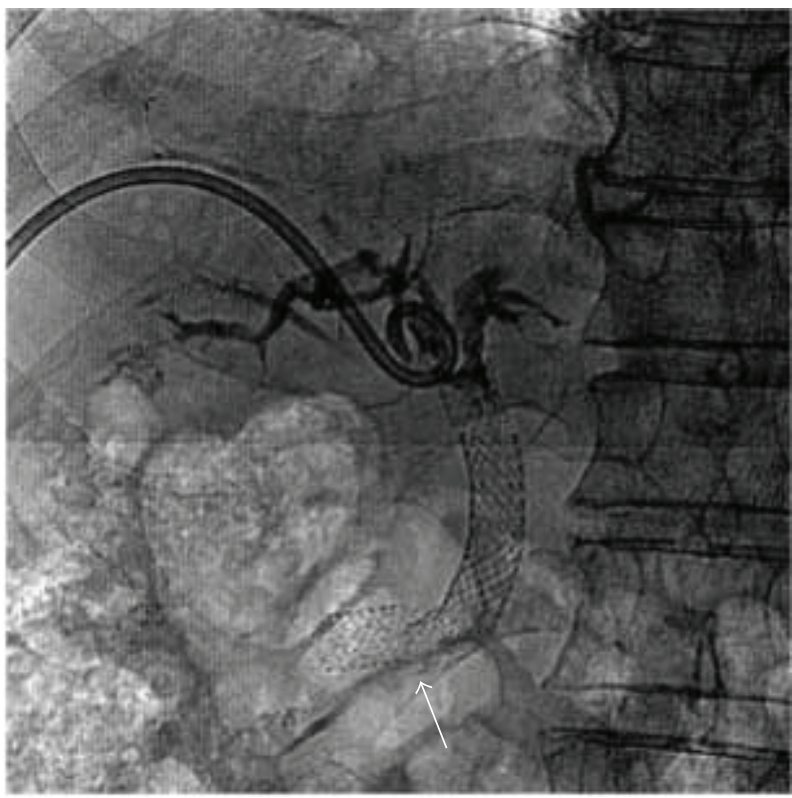

(d)

FIGURE 5: Fracture in a 71-year-old man with common bile duct obstruction secondary to cholangiocarcinoma. (a). Percutaneous transhepatic cholangiogram depicting common bile duct stricture was shown. (b). Two weeks later, a stent (diameter, $10 \mathrm{~mm}$; length, $40 \mathrm{~mm}$; COOK Inc., Bloomington, IN, United States) was inserted into the biliary stricture, above the duodenal ampulla. (c). Nine months after stent placement, the patient developed reobstructive jaundice, and percutaneous cholangiography revealed stent occlusion. Another biliary stent (diameter, $10 \mathrm{~mm}$; length, $100 \mathrm{~mm}$; COOK Inc., Bloomington, IN, United States) was deployed, extending from the duodenum to the convergence of the left and right hepatic ducts. An obtuse angle was formed between the two biliary stents (arrow). (d). One hundred and forty-two days after the second biliary stent implantation, plain X-ray showed the stent fracture located at the duodenal ampulla (arrow).

is the standard treatment option $[12,13]$. There are two techniques for biliary stent insertion, including endoscopic and percutaneous hepatic approaches; nevertheless, there has not been a uniform conclusion published on either the efficacy of the two types of drainage or the incidence rate of complications. The procedure's success rate is nearly $100 \%[5]$.
Common short and long-term complications include cholangitis, asymptomatic increase of amylase, and occlusion due to tumor ingrowth or overgrowth $[14,15]$. To the best of our knowledge, only 7 reports have described a total of 13 patients with fractures of metallic biliary stents placed to relieve malignant biliary obstruction (Table 4) [5-11]. The incidence of biliary stent fracture is approximately $7-22 \%$ 


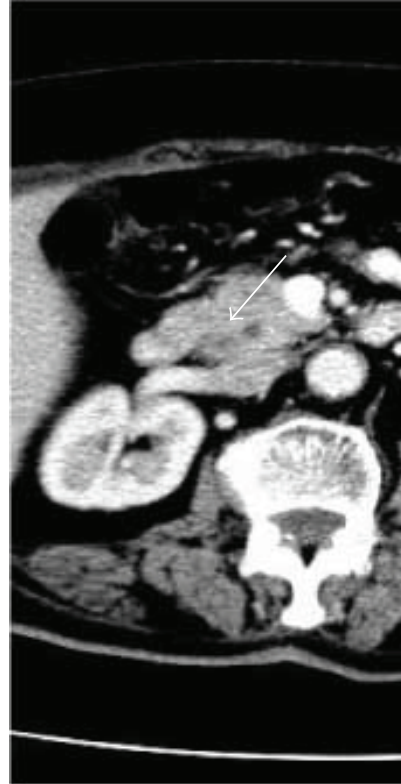

(a)

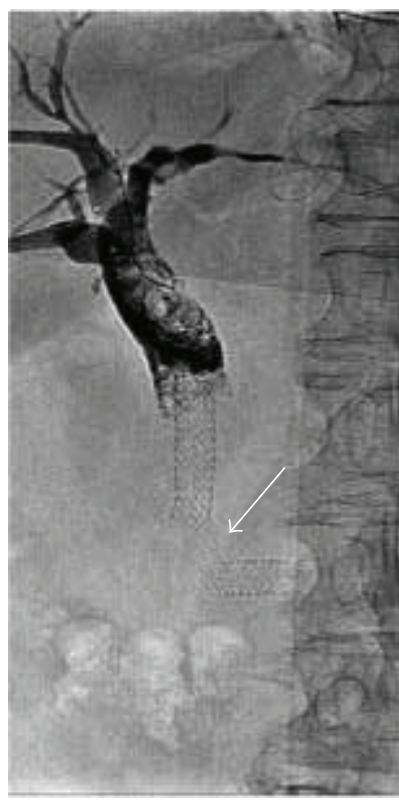

(d)

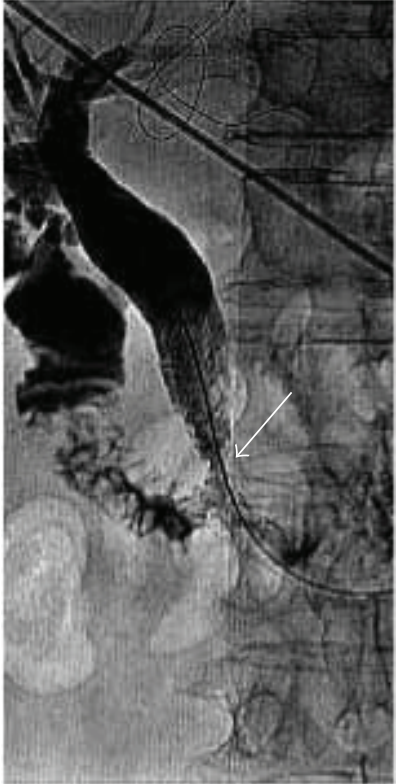

(b)

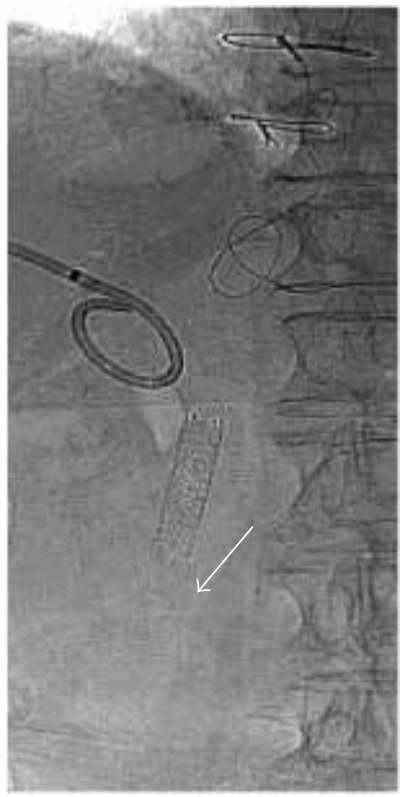

(e)

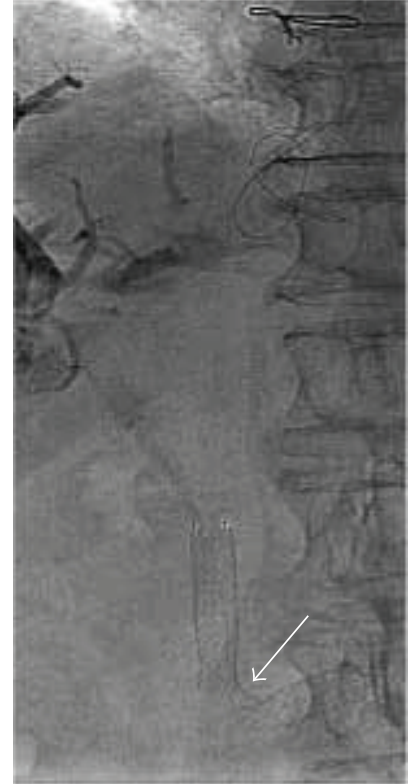

(c)

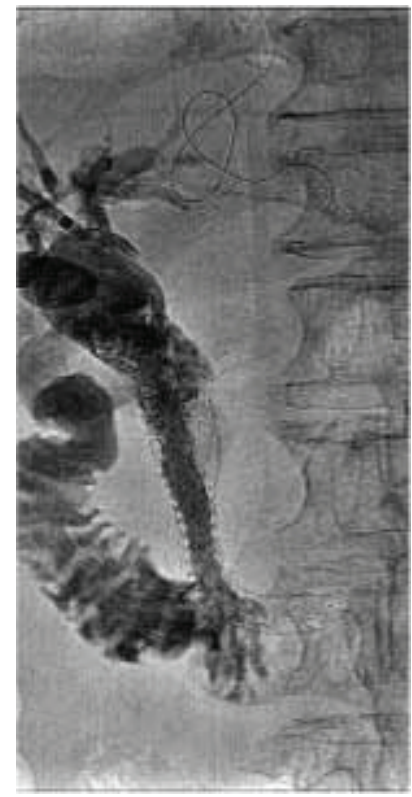

(f)

FIgURE 6: Gradual fracture of a biliary stent in a 78-year-old woman with common bile duct obstruction secondary to carcinoma of the ampulla of Vater. (a). Abdominal-enhanced CT scan showing a mass located at the duodenal ampulla of Vater (arrow) was shown. (b). Percutaneous transhepatic cholangiogram showing severe stricture of the distal common bile duct was shown, and a SEMS (diameter, $8 \mathrm{~mm}$; length, $60 \mathrm{~mm}$; COOK Inc., Bloomington, IN, United States) was inserted to relieve the obstruction. (c)-(e). 249 days after SEMS insertion, percutaneous transhepatic cholangiography showed stent fracture located at the stricture position, from partial, filamentous connective to complete fracture, without the distal part of the stent (arrow). (f). A new SEMS (diameter, $8 \mathrm{~mm}$; length, $80 \mathrm{~mm}$; COOK Inc., Bloomington, IN, United States) was inserted to relieve the reobstruction.

$[7,9]$; in this study, it was $3.8 \%$. Biliary reobstruction is expected from disease progression, but stent failure due to fracture is usually not suspected and thus probably overlooked and underreported. Therefore, it is difficult to estimate the exact incidence rate of biliary stent fractures.

Nitinol is an alloy consisting of 55\% nickel and $45 \%$ titanium. Its biocompatibility as well as unusual and useful properties of shape memory explains its widespread use in medicine. Stents may be exposed to significant stressinduced fatigue, which may weaken the metallic structure over time, leading to subsequent fracture and fragmentation [16]. Nitinol SEMSs are widely used in the management of stenosis affecting vascular and nonvascular vessels, such as the coronary artery, lower extremity artery, subclavian vein, and esophagus [16-21]. The most common factors which may affect stent fractures may include balloon dilation or 
TABLE 4: Previous reports assessing metallic biliary stent fractures.

\begin{tabular}{|c|c|c|c|c|c|c|}
\hline $\begin{array}{l}\text { Authors } \\
\text { (years) }\end{array}$ & Patients & Primary disease & Time to fracture & $\begin{array}{l}\text { Number of } \\
\text { stents }\end{array}$ & $\begin{array}{c}\text { Type of } \\
\text { stent }\end{array}$ & $\begin{array}{l}\text { Treatment of stent } \\
\text { fracture }\end{array}$ \\
\hline $\begin{array}{l}\text { Peck and } \\
\text { Wattam [7] }\end{array}$ & $\begin{array}{c}n=4 / 66^{*} \\
\text { Female }(n=3) \\
\text { Male }(n=1) \\
\text { Age, } 78.5 \pm 5.6 \\
\text { years }\end{array}$ & $\begin{array}{c}\text { Pancreatic carcinoma } \\
(n=2) \text {; cholangiocarcinoma } \\
(n=1) \text {; recurrent cholangitis } \\
(n=1)\end{array}$ & $\begin{array}{l}\text { Median fracture } \\
\text { times, } 225 \text { days }\end{array}$ & $\begin{array}{l}\text { One stent in } \\
\text { each patient }\end{array}$ & $\begin{array}{l}\text { Nitinol } \\
\text { stent }\end{array}$ & Reimplantation \\
\hline $\begin{array}{l}\text { Yoshida et al. } \\
\text { [5] }\end{array}$ & 82 , male & Pancreatic carcinoma & 5 months & One & $\begin{array}{c}\text { Nitinol } \\
\text { stent }\end{array}$ & Reimplantation \\
\hline $\begin{array}{l}\text { Sriram et al. } \\
{[10]}\end{array}$ & 63 , female & Cholangiocarcinoma & 6 months & One & $\begin{array}{c}\text { Nitinol } \\
\text { stent }\end{array}$ & Reimplantation \\
\hline $\begin{array}{l}\text { Yoshida et al. } \\
{[6]}\end{array}$ & 82 , male & Cholangiocarcinoma & 18 months & Two & $\begin{array}{l}\text { Nitinol } \\
\text { stent }\end{array}$ & Reimplantation \\
\hline $\begin{array}{l}\text { Rasmussen } \\
\text { et al. [9] }\end{array}$ & $\begin{array}{l}\quad n=4 / 48 \\
\text { Female }(n=3) \\
\text { Male }(n=1) \\
\text { Age, } 71.3 \\
\pm 13.8 \text { years }\end{array}$ & $\begin{array}{l}\text { Cancer of the papilla of Vater } \\
\qquad(n=1) ; \text { pancreatic } \\
(n=3)\end{array}$ & $\begin{array}{l}\text { Median fracture } \\
\text { times, } 392 \text { days }\end{array}$ & $\begin{array}{l}\text { One stent in } \\
\text { each patient }\end{array}$ & $\begin{array}{l}\text { Nitinol } \\
\text { stent }\end{array}$ & Reimplantation \\
\hline $\begin{array}{l}\text { Saravanan } \\
\text { et al. [8] }\end{array}$ & 50 , male & $\begin{array}{c}\text { Benign biliary anastomotic } \\
\text { stricture }\end{array}$ & NA & One & $\begin{array}{l}\text { Nitinol } \\
\text { stent }\end{array}$ & The surgical intervention \\
\hline $\begin{array}{l}\text { Alkhiari et al. } \\
{[11]}\end{array}$ & 67 , female & Recurrent cholangitis & NA & One & $\begin{array}{c}\text { Nitinol } \\
\text { stent }\end{array}$ & $\begin{array}{l}\text { Remove the fractured } \\
\text { stent by endoscopy }\end{array}$ \\
\hline
\end{tabular}

${ }^{*}$ Biliary stent fractures occurred in $4 / 66$ patients after biliary stent implantation.

stent overexpansion, stent overlap, stent length, stent type and stent conformability, and tortuous and highly angulated vessels $[13,22]$. The anatomic sites of biliary stent fractures varied; most were located at overlapping stents, tumor sites, or the ampulla, with distal stent disconnection. This may be related to increased cutting force, which caused significant stress-induced fatigue and resulted in fracture. The possibility of disease- or treatment-related factors leading to stent fracture has been considered.

The present study showed that the multistent fracture rate $(16.7 \%)$ was higher than the single stent counterparts $(2.8 \%)(P=0.07)$. The differences not reaching statistical significance may be due to the small sample size. The interactions between the stents and stent geometry during multistent implantation are considered the most important factor in biliary obstruction fractures. In addition, duodenal peristalsis and tumor compression can promote stent fracture occurrence. Operation-related factors, such as selecting stent size, passing the stent across the ampulla $(P=0.09)$, and pre- or postdilation $(P=0.10)$, may also contribute to stent fracture development [17]. Concerning stent patency time, no significant difference between the fracture and nonfracture groups was obtained $(P=0.52)$. As shown above, the survival time difference $(P=0.16)$ may be related to the advanced age of patients, low-grade malignancy, and the small sample size. Treatment of biliary stent fractures includes reimplantation of the biliary stent, indwelling of a new biliary drainage catheter, and partial removal of the fractured stent by endoscopy.

In conclusion, stent fracture occurs after insertion of selfexpanding nitinol stents for the treatment of malignant biliary obstruction, as a relatively rare long-term complication. The reported low incidence of this complication may be due to lack of awareness about stent fractures and the difficulty in detecting them. Though there were no factors found to be significantly associated with SEMSs fracture, a trend could be observed towards more fractures in multistent, transpapillary, and balloon dilation groups.

\section{Conflicts of Interest}

The authors declare that they have no conflicts of interest.

\section{References}

[1] S. Jaganmohan and J. H. Lee, "Self-expandable metal stents in malignant biliary obstruction," Expert Review of Gastroenterology \& Hepatology, vol. 6, no. 1, pp. 105-114, 2014.

[2] L. Z. C. T. Pu, R. Singh, C. K. Loong, and E. G. H. de Moura, "Malignant biliary obstruction: evidence for best practice," Gastroenterology Research and Practice, vol. 2016, Article ID 3296801, 7 pages, 2016.

[3] M. A. Almadi, A. Barkun, and M. Martel, "Plastic vs. selfexpandable metal stents for palliation in malignant biliary obstruction: a series of meta-analyses," The American Journal of Gastroenterology, vol. 112, no. 2, pp. 260-273, 2017.

[4] R. J. H. Schaafsma, P. Spoelstra, J. Pakan, and K. Huibregtse, "Sigmoid perforation: a rare complication of a migrated biliary endoprosthesis," Endoscopy, vol. 28, no. 5, pp. 469-470, 1996.

[5] H. Yoshida, T. Tajiri, Y. Mamada et al., "Fracture of a biliary expandable metallic stent," Gastrointestinal Endoscopy, vol. 60, no. 4, pp. 655-658, 2004.

[6] H. Yoshida, Y. Mamada, N. Taniai et al., "Fracture of an expandable metallic stent placed for biliary obstruction due to common bile duct carcinoma," Journal of Nippon Medical School, vol. 73, no. 3, pp. 164-168, 2006. 
[7] R. Peck and J. Wattam, "Fracture of memotherm metallic stents in the biliary tract," CardioVascular and Interventional Radiology, vol. 23, no. 1, pp. 55-56, 2000.

[8] M. N. Saravanan, V. Mathai, D. Kapoor, and B. Singh, "Fractured metallic biliary stent causing obstruction and jejunal perforation," Asian Journal of Endoscopic Surgery, vol. 6, no. 3, pp. 234-236, 2013.

[9] I. C. Rasmussen, U. Dahlstrand, G. Sandblom, L. G. Eriksson, and R. Nyman, "Fractures of self-expanding metallic stents in periampullary malignant biliary obstruction," Acta Radiologica, vol. 50, no. 7, pp. 730-737, 2009.

[10] P. V. Sriram, A. Ramakrishnan, G. V. Rao, and D. Nageshwar Reddy, "Spontaneous fracture of a biliary self-expanding metal stent," Endoscopy, vol. 36, no. 11, pp. 1035-1036, 2004.

[11] R. Alkhiari, V. Patel, and L. Cohen, "Spontaneous fracture of a covered self-expandable biliary metal stent and endoscopic technique for removal," Canadian Journal of Gastroenterology and Hepatology, vol. 28, no. 8, 412 pages, 2014.

[12] J. Y. Kim, G. B. Ko, T. H. Lee et al., "Partially covered metal stents may not prolong stent patency compared to uncovered stents in unresectable malignant distal biliary obstruction," Gut and Liver, vol. 11, no. 3, pp. 440-446, 2017.

[13] P. Rossi, M. Bezzi, M. Rossi et al., "Metallic stents in malignant biliary obstruction: results of a multicenter European study of 240 patients," Journal of Vascular and Interventional Radiology, vol. 5, no. 2, pp. 279-285, 1994.

[14] H. Yarmohammadi and A. M. Covey, "Percutaneous biliary interventions and complications in malignant bile duct obstruction," Chinese Clinical Oncology, vol. 5, no. 5, p. 68, 2016.

[15] S. J. Lee, M. D. Kim, M. S. Lee et al., "Comparison of the efficacy of covered versus uncovered metallic stents in treating inoperable malignant common bile duct obstruction: a randomized trial," Journal of Vascular and Interventional Radiology, vol. 25, no. 12, pp. 1912-1920, 2014.

[16] H. S. Khara, D. L. Diehl, and S. A. Gross, "Esophageal stent fracture: case report and review of the literature," World Journal of Gastroenterology, vol. 20, no. 10, pp. 2715-2720, 2014.

[17] M. Chinikar and P. Sadeghipour, "Coronary stent fracture: a recently appreciated phenomenon with clinical relevance," Current Cardiology Reviews, vol. 10, no. 4, pp. 349-354, 2014.

[18] N. Neil, "Stent fracture in the superficial femoral and proximal popliteal arteries: literature summary and economic impacts," Perspectives in Vascular Surgery and Endovascular Therapy, vol. 25, no. 1-2, pp. 20-27, 2013.

[19] A. Mallios, K. Taubman, P. Claiborne, and J. Blebea, "Subclavian vein stent fracture and venous motion," Annals of Vascular Surgery, vol. 29, no. 7, pp. 1451.e1-1451.e4, 2015.

[20] G. Coppi, R. Moratto, J. Veronesi, E. Nicolosi, and R. Silingardi, "Carotid artery stent fracture identification and clinical relevance," Journal of Vascular Surgery, vol. 51, no. 6, pp. 1397-1405, 2010.

[21] F. Damas-De Los Santos, F. Colombo, A. Zuffi, and A. Cremonesi, "Vertebral-subclavian bifurcation treatment. "the wedding ring technique" for a vertebral in-stent restenosis associated with stent fracture," Gaceta Médica de México, vol. 151, no. 5, pp. 655-659, 2015.

[22] M. K. Mohsen, A. Alqahtani, and J. Al Suwaidi, "Stent fracture: how frequently is it recognized?," Heart Views, vol. 14, no. 2, pp. 72-81, 2013. 


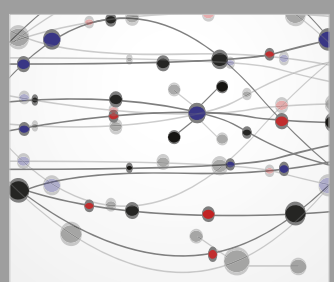

The Scientific World Journal
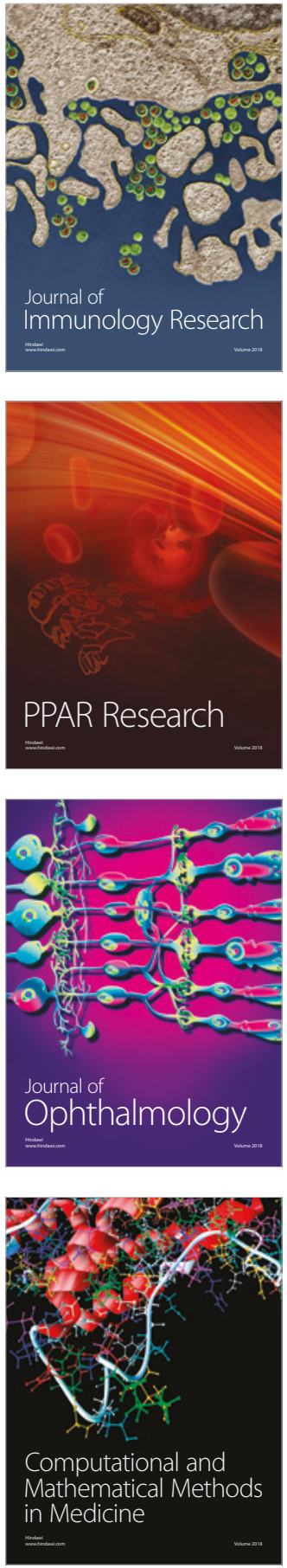

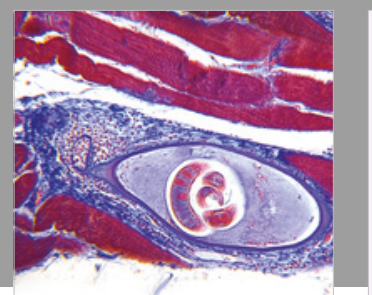

Gastroenterology Research and Practice

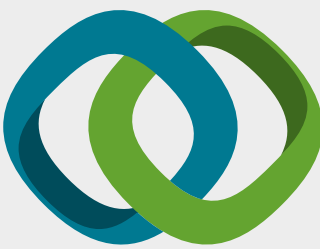

\section{Hindawi}

Submit your manuscripts at

www.hindawi.com
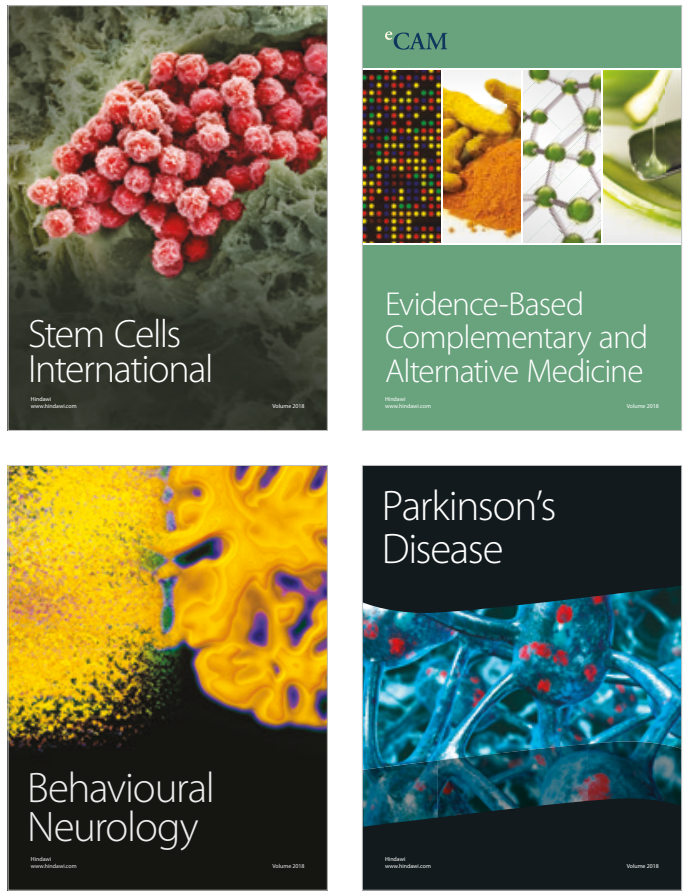

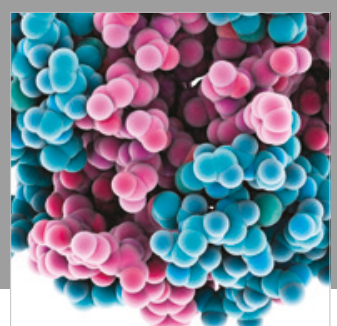

ournal of

Diabetes Research

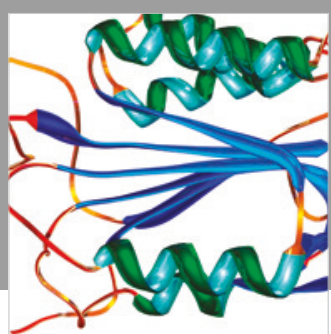

Disease Markers
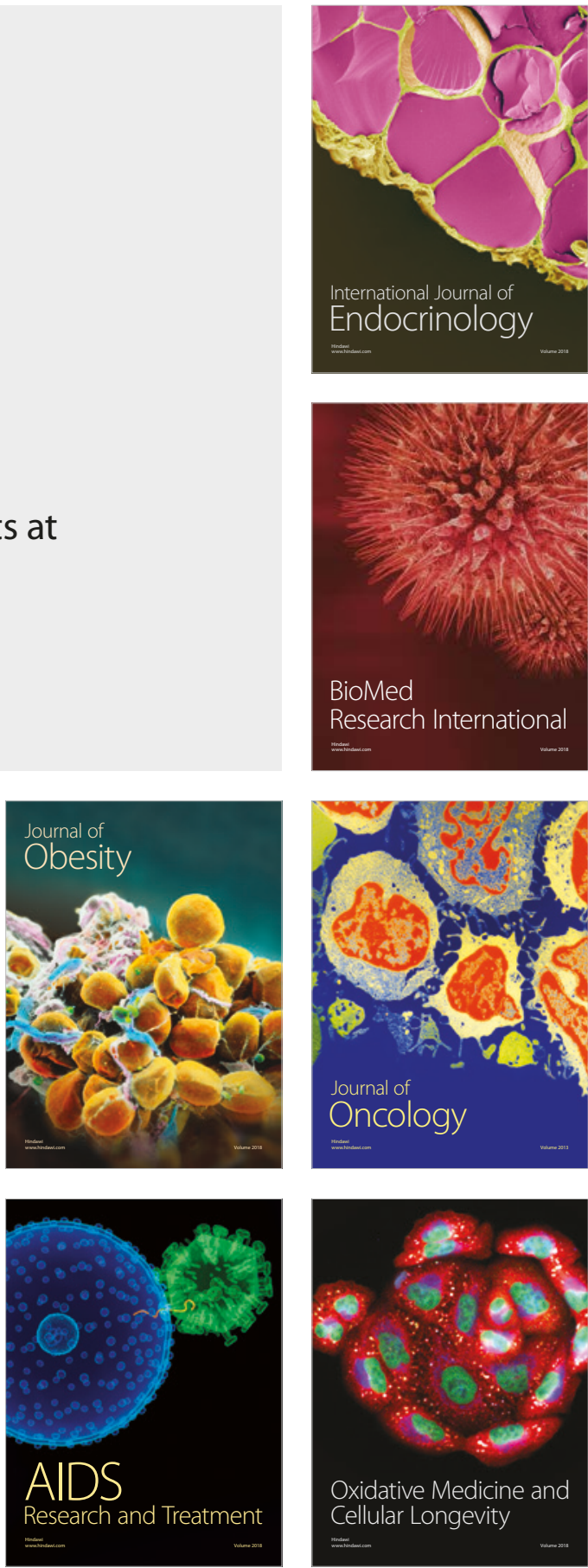